\title{
Response Gene to Complement-32 Promotes the Imbalance of Treg/Th17 in Patients with Dilated Cardiomyopathy
}

\author{
Bailing Li Wei Zhou Xiaojun Tang Wei Wang Jiajun Pan Mengwei Tan \\ Department of Cardiothoracic Surgery, Changhai Hospital, Second Military Medical University, \\ Shanghai, China
}

\section{Key Words}

Response gene to complement-32 • Dilated cardiomyopathy $\bullet$ IL- $17^{+}$Th17 cells • Foxp3 ${ }^{+}$Treg cells

\begin{abstract}
Background/Aims: The imbalance of Treg/Th17 cells plays important role in the pathogenesis of dilated cardiomyopathy (DCM). Response gene to complement (RGC)-32 is a cell cycle regulator that plays an important role in cell proliferation. We evaluated whether the upregulation of RGC-32 was implicated in the homeostasis of Treg/Th17 cells in DCM. Methods: The levels of plasma RGC-32, IL-17 and TGF- $\beta 1$, and the frequencies of circulating CD4 ${ }^{+}$RGC-32+ T cells, Th17 and Treg cells in patients with DCM were determined by Cytokinespecific sandwich ELISA and the flow cytometer (FCM), respectively. Results: A significant elevation of plasma RGC-32 in patients with DCM compared with healthy control $(\mathrm{HC})$ subjects was observed. This upregulation was associated with an increase in frequency of Th17 and a decrease in frequency of Treg cells. To further assessed the role of RGC-32, we investigated the effects of RGC-32 up- or down-regulation on frequencies of Th17 and Treg cells in peripheral blood mononuclear cells (PBMCs) from subjects. Importantly, overexpression of RGC-32 was accompanied by an augmentation of Th17 and a reduction of Treg expression. Conclusion: In summary, our study demonstrated the up-regulation of RGC-32 contributed to the imbalance of Treg/Th17 cells in patients with DCM.

(C) 2017 The Author(s)

Published by S. Karger AG, Basel

\section{Introduction}

Dilated cardiomyopathy (DCM) is a primary myocardial disorder characterized by ventricular chamber enlargement and systolic dysfunction of the left and/or right ventricle. The disease progression of DCM is highly diverse due to its aetiological and pathophysiological heterogeneity [1], and now appropriate treatment of DCM remains a major clinical challenge [2]. Although the immunopathogenesis of DCM remains unclear,
\end{abstract}


current clinical and experimental evidence has suggested that immune activation and the consequential inflammatory response in the myocardium may be involved in the development and progression of DCM $[3,4]$.

Response gene to complement (RGC)-32 is a novel molecule that may promote cell cycle progression in response to complement activation and has been implicated in proliferation of aortic smooth muscle cells [5]. The expression of RGC-32 was detected in placenta, liver, skeletal muscle, kidney, heart, brain, and pancreas. The mRNA was also detected in human aortic endothelial cells and JY25 B lymphoblastoid line and serum [5, 6]. In addition, increased expression of RGC-32 is found in the PBMCs and CD4 cells of patients with stable relapsingremitting multiple sclerosis (MS) [7]. Recently, Tegla et al. [7] reported that RGC-32 is upregulated in TCR-stimulated mouse $\mathrm{CD}^{+} \mathrm{T}$ cells. In RGC-32-deficient mice, demonstrated that RGC-32\% CD4+ $\mathrm{T}$ cells exhibited enhanced proliferation, IL-2 production, and Akt phosphorylation as compared with RGC- $32^{+/+} \mathrm{CD} 4^{+} \mathrm{T}$ cells, suggesting a down-regulatory role of RGC-32 under Th0 conditions [7]. Tegla and Vlaicu et al. reported increased expression of RGC-32 protein in macrophages, T cells, and astrocytes in the brain of patients with multiple sclerosis (MS) and in the colonic mucosa of patients with inflammatory bowel disease $[8,9]$.

Cellular and humoral autoimmunity have been involved in the pathological process of DCM, such as antibodies against the catalytic $\alpha$-subunit of sarcolemmal Na-K-ATPase, which were known to play a role in the pathophysiology of DCM [10,11]. Th17 cells (mainly related cytokines IL-17, IL-22) account for pro-inflammatory immune responses but damaging tissue, and Treg cells (mainly related cytokines TGF- $\beta 1$, IL-10) control inflammatory immune responses but hindering anti-inflammatory immunity. The mounting evidence indicates that two subsets of CD4+ $\mathrm{T}$ cells (i.e., Th17 and Treg cells) play an important role in the immunopathogenesis of inflammatory diseases, such as idiopathic DCM, MS, experimental autoimmune encephalomyelitis (EAE), and autoimmune thyroid diseases (AITDs) [12-14]. The work by Baldeviano et al. suggested a pivotal role for IL-17 in the progression to DCM in an experimental autoimmune model of myocarditis in mice, promoting a fibrotic response [15]. A higher proportion of Treg cells has been shown to be protective against both viral and autoimmune myocarditis in mouse models. Interestingly, further work by Chen et al. demonstrated that in autoimmune myocarditis a lower proportion of Treg cells was associated with a greater Th17 response and more severe autoimmune myocarditis [16]. An imbalance between Treg and Th17 cells has recently been observed in idiopathic DCM [12, 17]. In the study by Rus et al., the proportion of Th17 was significantly decreased in RGC32-deficient $\mathrm{CD}^{+}{ }^{+} \mathrm{T}$ cells under Th17 polarizing conditions [18]. Thus, we hypothesize that RGC-32 may promote process of DCM via regulating the imbalance of Treg/ Th17 ratio.

In this study, we examined the levels of plasma RGC-32 and the frequencies of circulating CD4 ${ }^{+}$RGC- $32^{+}$T cells, Th17 and Treg cells, and evaluated the relationship between the expression of RGC-32 and the frequency of Th17 or Treg cells as well as Treg/Th17 ratio in patients with DCM.

\section{Materials and Methods}

\section{Study population}

Between January 2013 and December 2016, 41 DCM-diagnosed patients without detectable etiology newly hospitalized and 39 healthy control (HC) subjects from Changhai Hospital, Second Military Medical University (Shanghai, China) were enrolled in this study. The diagnosis of DCM was based on the revised criteria established by the 1995 World Health Organization /International Society and Federation of Cardiology Task Forceon the Classification of Cardiomyopathy [19]. In this investigation, DCM was defined as systolic dysfunction [left ventricular ejection fraction (LVEF) < 45\%] with ventricular dilation [left ventricular end-diastolic diameter (LVEDD) > $55 \mathrm{~mm}$ ] in the absence of an apparent secondary cause of cardiomyopathy, such as coronary heart disease, hypertensive heart disease, or valvular heart disease [20]. The exclusion criteria included ischaemic cardiomyopathy, hypertrophic cardiomyopathy, hypertensive heart disease, a history of uncontrollable or untreated hypertension for at least a year before the documentation of LV 
dysfunction, and other secondary cardiomyopathies such as sarcoidosis and amyloidosis, the presence of significant coronary artery stenosis on angiography and non-ischaemic DCM secondary to valvular heart disease, systemic hypertension, cardiac surgery or acute myocarditis, excessive alcohol abuse, pregnancy, endocrine disease, active infectious disease or collagen disease, medical history of autoimmune disease [12, 21]. All subjects gave written informed consent and the protocol was reviewed. This study was approved by the Ethic Committee for Application of Human Samples, Second Military Medical University. The baseline characteristics of all enrolled subjects are presented in Table 1.

\section{Blood samples}

Heparinized peripheral blood samples (10 $\mathrm{mL})$ were obtained from all subjects after an overnight fast. Anticoagulated whole blood (2 $\mathrm{mL}$ ) is examined for the flow cytometer (FCM) within $4 \mathrm{~h}$. Plasma were stored at $-80^{\circ} \mathrm{C}$ for enzyme linked immunosorbent assay (ELISA) assays. PBMCs were isolated using Ficoll Hypaque (GE Healthcare Life Science, Shanghai, China) as previously described [22] for further culture.

\section{Plasma cytokines ELISA assay}

The serum levels of RGC-32, TGF- $\beta 1$, IL-10, IL-17 and IL-22 were quantified using cytokinespecific ELISA kits (RGC-32 kit from Biomatik, Wilmington, DE, USA, and the rest kits from eBioscience, San Diego, CA, USA) according to the manufacturer's instructions.
Table 1. The clinical baseline characteristics of the study population. Data are presented as mean \pm standard deviation or number (\%) of subjects. BMI: body mass index; NYHA, New York Heart Association; NTProBNP: N-terminal Pro-B-type natriuretic peptide; LVDD, left ventricular diastolic diameter; LVSD, left ventricular systolic diameter; LAD, left atrial diameter; LVEF, left ventricular ejection fraction; SBP, systolic blood pressure; DSP, diastolic blood pressure; PCWP, pulmonary capillary wedge pressure; RAP, right atrial pressure; ACE-I, angiotensin converting enzyme inhibitors; $\mathrm{ARB}$, angiotensin II receptor blocker; *The cardiac index is the cardiac output in litres per minute divided by the body surface area in square metres calculated with the formula $0.007184 \times$ weight $^{0.425} \times$ height $t^{0.725}$

\begin{tabular}{|c|c|c|c|}
\hline Characteristics & $\begin{array}{c}\text { DCM } \\
(n=41)\end{array}$ & $\begin{array}{c}\mathrm{HC} \\
(n=39)\end{array}$ & $p$ \\
\hline Age (years) & $50.1 \pm 4.3$ & $49.2 \pm 5.7$ & 0.896 \\
\hline \multicolumn{4}{|l|}{ Sex-no. (\%) } \\
\hline Male & $31(75.6)$ & $29(74.4)$ & 0.679 \\
\hline Female & $10(24.4)$ & $10(25.6)$ & 0.581 \\
\hline $\operatorname{BMI}\left(\mathrm{kg} / \mathrm{m}^{2}\right)$ & $22.7 \pm 3.8$ & $23.2 \pm 5.1$ & 0.725 \\
\hline Diabetes mellitus-no. (\%) & $6(14.6)$ & $6(15.4)$ & 0.444 \\
\hline \multicolumn{4}{|l|}{ NYHA- no. (\%) } \\
\hline II & $9(22.0)$ & $0(0)$ & $<0.001$ \\
\hline III & $21(51.2)$ & $0(0)$ & $<0.001$ \\
\hline IV & $11(26.8)$ & $0(0)$ & $<0.001$ \\
\hline NT-proBNP (pg/ml) & $7186 \pm 1001.2$ & $172 \pm 15$ & $<0.001$ \\
\hline \multicolumn{4}{|l|}{ Echocardiography } \\
\hline LVDD (mm) & $71 \pm 9.1$ & $44 \pm 6.3$ & $<0.001$ \\
\hline LVSD (mm) & $56 \pm 8.2$ & $30 \pm 4.5$ & 0.007 \\
\hline LAD (mm) & $45.6 \pm 7.8$ & $27 \pm 4.1$ & 0.003 \\
\hline LVEF(\%) & $30.1 \pm 8.3$ & $67 \pm 5.7$ & 0.006 \\
\hline \multicolumn{4}{|l|}{ Haemodynamics } \\
\hline HR (b.p.m) & $76 \pm 15$ & $72 \pm 10$ & 0.651 \\
\hline SBP (mmHg) & $119 \pm 21$ & $124 \pm 17$ & 0.803 \\
\hline DSP(mmHg) & $69 \pm 11$ & $74 \pm 8.7$ & 0.746 \\
\hline PCWP(mmHg) & $11.5 \pm 8$ & $11 \pm 6$ & 0.594 \\
\hline RAP(mmHg) & $4.1 \pm 3$ & $4 \pm 2$ & 0.702 \\
\hline Cardiac index $\left(\mathrm{L} / \mathrm{min} \cdot \mathrm{m}^{2}\right)^{*}$ & $3 \pm 0.4$ & $3.2 \pm 0.3$ & 0.822 \\
\hline \multicolumn{4}{|l|}{ Medications- no. (\%) } \\
\hline ACE-I/ARB & $29(70.7)$ & $2(5.1)$ & $<0.001$ \\
\hline Calcium blocker & $22(53.7)$ & $3(7.7)$ & $<0.001$ \\
\hline$\beta$-blocker & $10(24.4)$ & $1(2.6)$ & $<0.001$ \\
\hline Digitalis & $26(63.4)$ & $0(0)$ & $<0.001$ \\
\hline diuretics & $24(58.5)$ & $0(0)$ & $<0.001$ \\
\hline Nitrates & $19(46.3)$ & $0(0)$ & $<0.001$ \\
\hline
\end{tabular}




\section{Cellular Physiology Cell Physiol Biochem 2017;43:1515-1525 \begin{tabular}{l|l|l}
\hline and Biochemistry $10.1159 / 000481975$ & $\begin{array}{l}\text { C } 2017 \text { The Author(s). Published by S. Karger AG, Basel } \\
\text { www.karger.com/cpb }\end{array}$ \\
\hline
\end{tabular}}

Li et al.: RGC-32 Promotes Treg/Th17 Imbalance in DCM

\section{Flow cytometry}

PE- or FITC-conjugated anti-CD4, APC-conjugated anti-CD25, PerCP-Cy5.5-labeled anti-FoxP3 and PEconjugated anti-IL-17 mAbs were purchased from BD Biosciences (San Jose, CA, USA). Primary rabbit antihuman RGC-32 Ab was detected using secondary FITC-labeled goat anti-rabbit Ab (Santa Cruz Biotechnology, Dallas, TX, USA). Measurement of CD $4^{+} \mathrm{CD} 25^{+}$Foxp $3^{+}$Treg, CD $4^{+} \mathrm{IL} 7^{+} \mathrm{Th} 17$ cells, and CD4 ${ }^{+} \mathrm{RGC}-32^{+} \mathrm{T}$ cells was performed by flow cytometry using intracellular staining as previously described with minor modifications $[23,24]$. Briefly, Aliquots of heparinized whole blood $(100 \mu \mathrm{L})$ and cultured PBMCs were surface labeled with antibodies of each subpopulation for $15 \mathrm{~min}$ at room temperature (RT). Erythrocytes were lysed using lysing solution. Following fixation and permeabilization, intracellular staining of FoxP3, IL-17, and RGC32 was performed according to the manufacturer's instructions. For intracellular cytokine staining, cells were stimulated with 50ng/mL PMA (Sigma-Aldrich) and $1 \mathrm{mg} / \mathrm{ml}$ ionomycin (Sigma-Aldrich) for $4 \mathrm{~h}$, and GolgiPlug was added for the last $2 \mathrm{~h}$ (BD Biosciences). The cells were analyzed by FCM (FASCcan or FACS Vantage SE; BD Biosciences). Data analysis was performed using CellQuest software (BD Biosciences).

\section{Plasmid, siRNA and PBMCs transfection}

The human RGC-32 expression plasmid (pcDNA3.1-RGC-32) was constructed as previously described [25]. After freshly isolated PBMCs were cultured in standard supplemented serum-free media (Gibco, Auckland, USA ) for 24h, a part of cells were nucleofected with RGC-32 or control plasmids using Nucleofector (Amexa Biosystems, Cologne, Germany) according to the manufacturer's instructions and as previously described [26]. For transient knockdown of RGC-32, siRNA against human RGC-32 (Santa Cruz Biotech, Santa Cruz, CA, USA) was nucleofected into the resting PBMCs using Nucleofector kit for human primary T cells (Amaxa, Gaithersberg, MD, USA) according to the manufacturer's instructions. A scrambled siRNA was used as control [8]. The efficiency of transfection for RGC-32 was confirmed by Western blotting.

\section{Cells treatments}

Cells were harvested at $48 \mathrm{~h}$ after PBMCs transfection. And then, cells were stimulated with $4 \mu \mathrm{L} /$ $\mathrm{mL}$ phorbolmyristate acetate (PMA)/Ionomycin mixture (Lot LK-CS1001, Liankebio, China) for $6 \mathrm{~h}$ in the presence of $4 \mu \mathrm{L} / \mathrm{mL}$ BFA/Monensin mixture (Lot LK- CS1002, Liankebio, China) [23].The proportions of cells $\mathrm{CD} 4^{+} \mathrm{IL}_{-17}-7^{+} \mathrm{Th} 17$ and $\mathrm{CD} 4{ }^{+} \mathrm{CD} 25^{+}$Foxp3 ${ }^{+}$Treg cells were determined by flow cytometry analysis and the levels of TGF- $\beta$, IL-10, IL-17 and IL-22 in the supernatants were measured by ELISA.

\section{Statistical analysis}

Statistical analyses were performed in the SPSS 19.0 statistical software package. For comparison between two groups, data were analyzed with the Student's $t$ test, and One-way analysis of variance (ANOVA) was used to evaluate the differences among multiple groups Pearson correlation was applied to assess correlation analysis. A two-tailed $p<0.05$ was considered as statistically significant.

\section{Ethical Approval}

All procedures performed in studies involving human participants were in accordance with the ethical standards of the institutional and/or national research committee and with the 1964 Helsinki Declaration and its later amendments or comparable ethical standards.

\section{Informed Consent}

Informed consent was obtained from all individual participants included in the study.

\section{Results}

Patients with DCM Exhibit Elevated Levels of Plasma RGC-32 and Circulating Th17 cells

To investigate any correlation between the RGC-32 levels and the frequency of Treg or Th17 cells, we measured the frequencies of circulating CD4 ${ }^{+} \mathrm{CD} 25^{+}$Foxp $3^{+} \mathrm{Treg}^{\mathrm{CD}} 4^{+} \mathrm{IL}-17^{+}$ Th17 cells and $\mathrm{CD}^{+}{ }^{+} \mathrm{RGC}-32^{+} \mathrm{T}$ cells by FCM, and the levels of plasma RGC-32 by cytokinespecific ELISA in patients with DCM and healthy control (HC) subjects. CD4 ${ }^{+} \mathrm{T}$ cells or serum from DCM contained an elevated level of RGC-32 compared with healthy control (HC) 


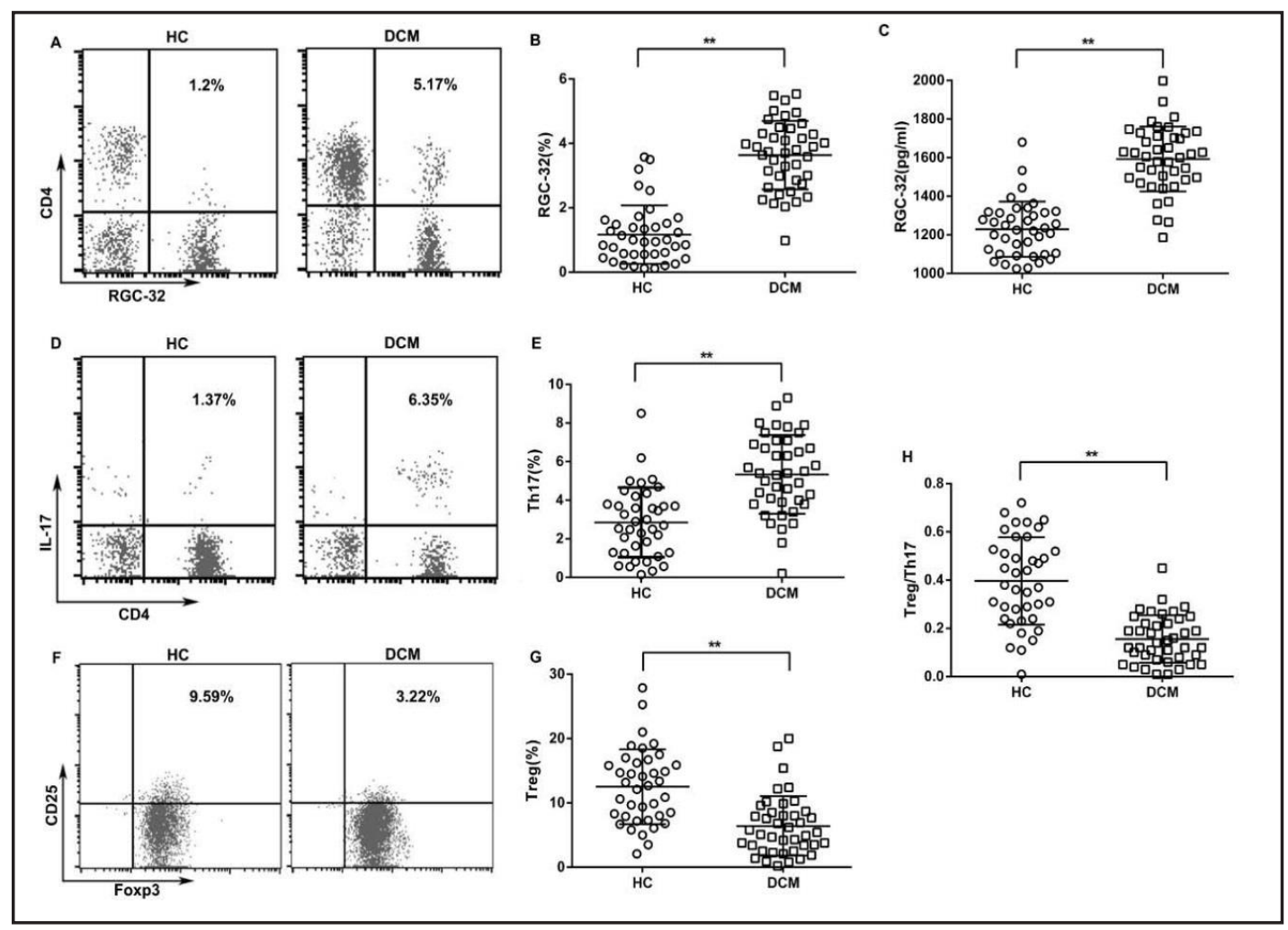

Fig. 1. The expression of response gene to complement-32 (RGC-32) and circulating Th17, Treg cells in patients with dilated cardiomyopathy (DCM) and healthy controls (HC). (A) Representative dot plots of CD4 ${ }^{+}$RGC- $32^{+}$T cells, CD4 ${ }^{+} \mathrm{IL}_{-17^{+}}$Th17 cells (D), and CD4 ${ }^{+} \mathrm{CD} 25^{+}$FoxP3 ${ }^{+}$Tregs (F). CD25 $5^{+}$FoxP3 ${ }^{+}$Tregs were gated from the $\mathrm{CD}^{+}$subset of $\mathrm{CD}^{+}{ }^{+} \mathrm{T}$ cells. (B) Frequencies of CD4+ ${ }^{+} \mathrm{RGC}-32^{+} \mathrm{T}$ cells, CD4+ IL-17+ ${ }^{+}$Th17 (Th17) cells (E), and CD25 ${ }^{+}$Foxp $^{+}$T regulatory (Treg) cells (G). (C) Cytokine-specific ELISA for RGC-32 determined in plasma. (H) The ratio of Treg/Th17 cells. Each symbol represents an individual subject; Data are shown mean \pm SD; ${ }^{* *} \mathrm{p}<0.01(\mathrm{DCM}, \mathrm{n}=41 ; \mathrm{HC}, \mathrm{n}=31)$.

subjects (Fig. 1A, B, and C). Interestingly, alongside increased RGC-32 levels, the frequency of Th17 was significantly elevated and while the frequency of Treg cells was significantly reduced in DCM patients compared to healthy subjects (Fig. 1 D, E, F, and G).

Treg/Th17ratio may be important in the development/prevention of autoimmune diseases [27]. The Treg/Th17 ratio was significantly decreased in patients with DCM compared to healthy control subjects (Fig. $1 \mathrm{H}$ ).

\section{Dysregulated Cytokine Profile in Patients with DCM}

Augmented immunoactivation in patients with DCM was also reflected by an increased number of plasma Th17-produced proinflammatory cytokine IL-17 and IL-22 concentrations (Fig. 2 A). In contrast, the peripheral blood levels of Treg-generated immunosuppressive cytokine TGF- $\beta 1$ and IL-10 were significantly reduced in patients with DCM (Fig. 2B). These data were consistent with the frequencies of circulating Th17 and Treg cells. Therefore, our results demonstrate that the plasma cytokine milieu and immune cell profiles in patients with DCM are skewed toward a proinflammatory phenotype.

Correlations of RGC-32 Levels with Frequencies of Treg and Th17 cells and Treg /Th17 Ratio

To explore whether there was a relationship between RGC-32 expressions and frequencies of Th17 or Treg cells, correlation analyses were performed. As shown in Fig $3 \mathrm{~A}$, levels of RGC-32 did not correlate with the frequencies of circulating Treg and Th17 cells as 


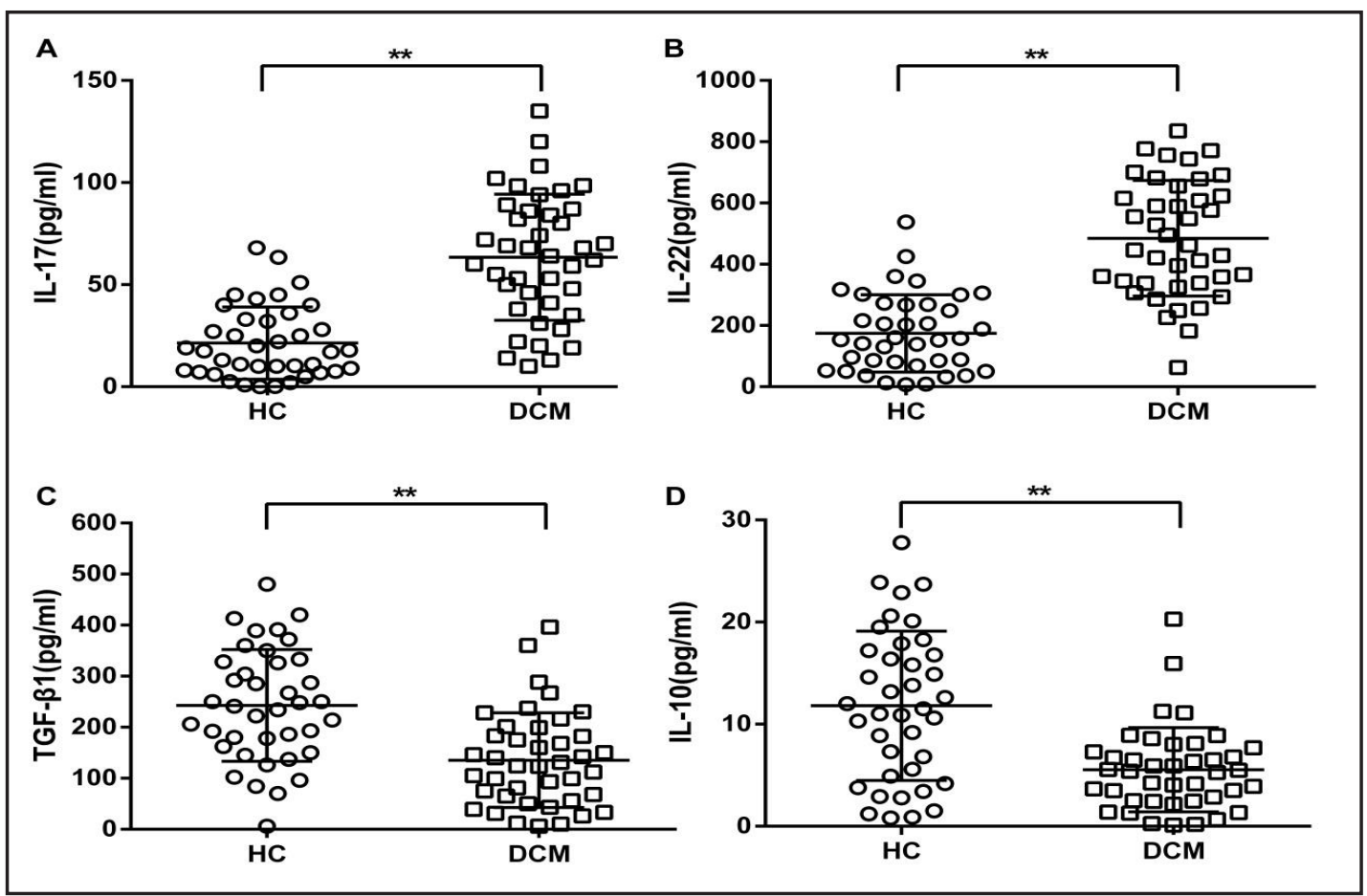

Fig. 2. The levels of the related cytokines produced by Th17 or Treg cells in DCM. Cytokine-specific sandwich ELISA of plasma from patients with DCM and healthy control subjects were performed to measure the levels of circulating (A) interleukin (IL)-17 and IL-22, (B) transforming growth factor (TGF)- $\beta 1$ and IL-10. Each symbol represents an individual subject; Data are shown mean \pm SD; ${ }^{* *} \mathrm{p}<0.01$ (DCM, $\mathrm{n}=41 ; \mathrm{HC}, \mathrm{n}=31$ ).

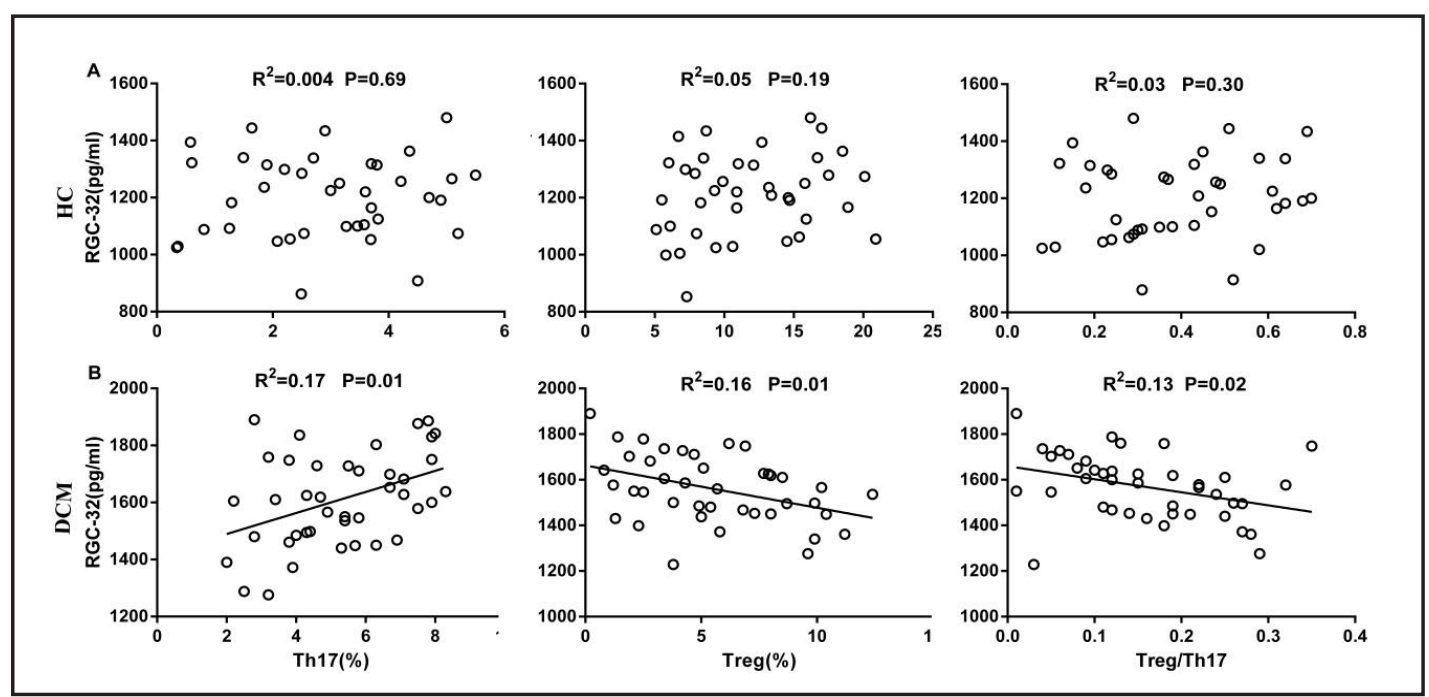

Fig. 3. Correlation of plasma RGC-32 levels with immune parameters of patients with DCM. Correlation of plasma RGC-32 levels with frequencies of Th17 and Treg cells and the ratio of Treg /Th17 cells in (A) HC group (n=39), (B) DCM group (n=41). Each symbol represents an individual subject.

well as ratio of Treg/Th17 in healthy subjects. Strikingly, elevated levels of RGC-32 in DCM patients exhibited a positive relationship with frequency of Th17 and a negative correlation with frequency of Treg and ration of Treg/Th17 cells (Fig 3 B), suggesting that expressions of RGC-32 may play an crucial role in the imbalance of Treg/Th17 ratio in patients with DCM. 


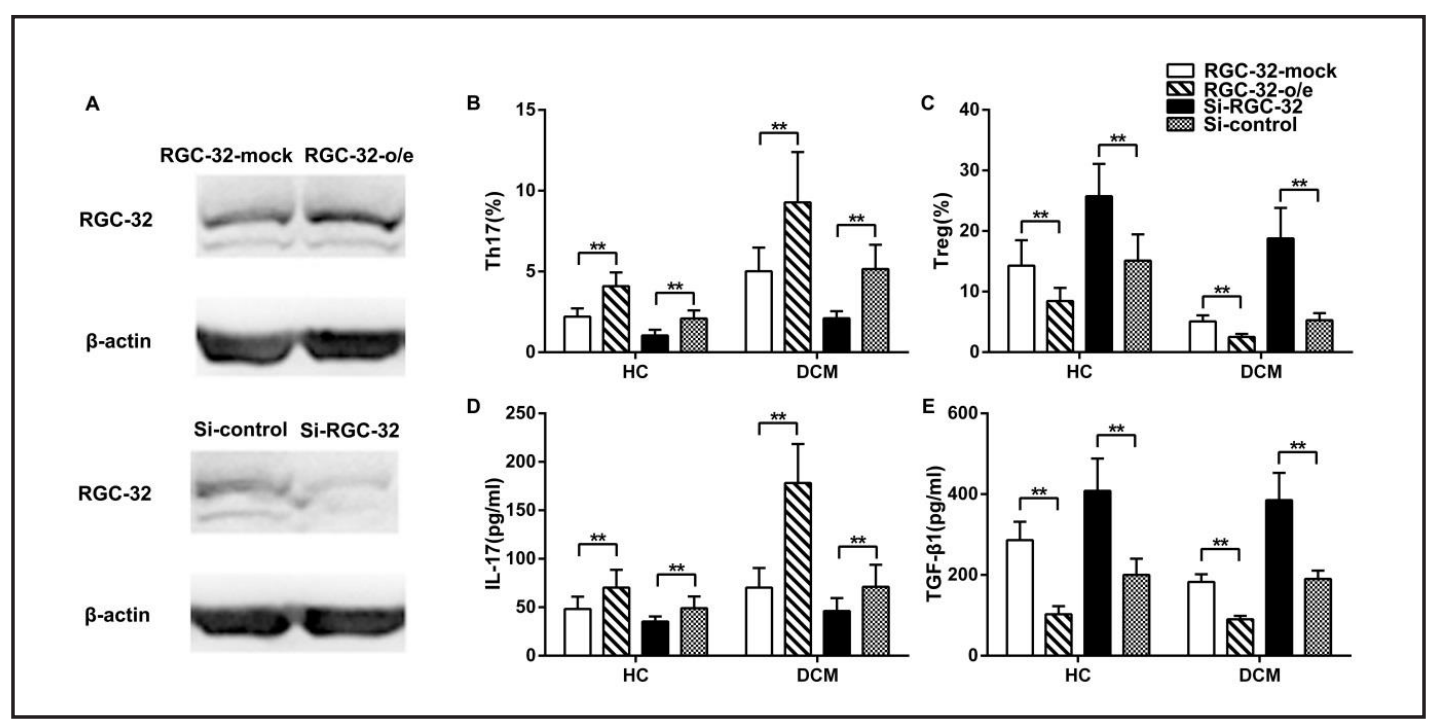

Fig. 4. Alterations of RGC-32 expression levels in PBMCs affect the frequencies of Th17 and Treg cells. PBMCs from patients with DCM were transfected with RGC-32-Plasmid or RGC-32-siRNA as described in the Materials and methods section. (A) Western blot analysis of RGC-32 expression in transfected cells. Representative blots of three independent experiments are shown. $\beta$-actin was used as a loading control. o/e: overexpression. At $48 \mathrm{~h}$ after transfection, and then were challenged with $4 \mu \mathrm{L} / \mathrm{mL} \mathrm{PMA} /$ Ionomycin mixture for additional $6 \mathrm{~h}$. Subsequently, Cells were determined (A) expression of Th17 and (B) Treg cells by FCM. Cytokine-specific sandwich ELISA of the culture supernatants was performed to measure (C) the levels of secretory IL-17and (D) TGF- $\beta 1$. Data are the means of triplicate independent experiments; ${ }^{* *} \mathrm{p}<0.01$.

Dysregulated Expression of RGC-32 Affect the Frequencies of Treg and Th17 Cells

To determine whether alterations of RGC-32 expression affect proportions of Treg and Th17 cells, PBMCs from patients with DCM and healthy control subjects were transfected with RGC-32-plasmid or RGC-32-siRNA for $24 \mathrm{~h}$ as described in Materials and Methods. As shown in Fig 4A, RGC-32 protein expression was effectively upregulated and reduced using the RGC-32 specific plasmid and siRNA, respectively. FCM analysis showed that the overexpression of RGC-32 resulted in the increment in Th17 frequency and the reduction of Treg frequency, whereas downregulation of RGC-32 expression declined the frequency of Th17 cells and promoted the elevation of Treg cells (Fig 4B and 4C). The levels of IL-17 and TGF- $\beta 1$ were consistent with the expressions of Th17 and Treg (Fig 4D and 4E). Similar secretion of cytokines was observed in cytokines IL-22 and IL-10 (data not shown).

\section{Discussion}

In this study, we demonstrated that the elevation of plasma RGC-32 in patients with DCM and found that the aberrant expressions of RGC-32 affected the proportions of Treg and Th17 cells. It is noteworthy that the levels of RGC-32 negatively correlated with the Treg/Th17 ratio in DCM. These data suggest that RGC-32 may be contributed to the process of DCM by modulating the Treg/Th17 ratio, which potentially serves as new target of DCM treatment.

Accumulating evidence demonstrated the dysregulated expression of RGC-32 in human malignancies, hyper-immunoglobulin E syndrome, and fibrosis. RCG-32 expression is upregulated in cutaneous $\mathrm{T}$ cell lymphoma, colon, ovarian, and breast cancer, and but downregulated in invasive prostate cancer, multiple myeloma, and drug-resistant glioblastoma [28]. RGC-32 plays a role in the immune response which has been determined 
by the gene expression studies of Tanaka et al. in hyper-immunoglobuline E syndrome (HIES) patients [29]. Recent studies reported that levels of RGC-32 mRNA in PBMCs were significantly higher in patients with stable SM as compared with patients who had a relapse (active disease) [8] and the RGC-32 protein expressions in macrophages and T cells were significantly increased in the colonic mucosa of patients with inflammatory bowel disease [9]. Our study demonstrates that not only the plasma RGC-32 levels but intracellular RGC32 expression of $\mathrm{CD} 4^{+} \mathrm{T}$ cells were also significantly increased in DCM patients. The results indicate RGC-32 upregulation appears to strengthen immune activation and promote inflammatory responses.

Th17 and Treg cells play a critical role in maintaining the homeostasis. Th17 cells function as the important mediators during the pathogenesis of chronic inflammatory disorders via the production of IL-17, IL-21 and IL-22 [30]. These cells and cytokines are involved in the pathogenesis of MS, adrimycin-induced nephropathy, and other autoimmune diseases [31-37], and promote the progression to DCM [15]. In contrast, Treg cells inhibit the immune response, inflammation, and tissue destruction by producing the anti-inflammatory cytokines (TGF-ßand IL-10) and suppressing the function of other lymphocytes [38, 39]. Treg/Th17 imbalance has a crucial role in induction and maintenance of sterile chronic inflammation [40]. In this study, the frequency of Th17 cells was significantly elevated and whereas the percentage of Treg cells drastically decreased in DCM patients compared with healthy control subjects. On the other hand, the ratio of Treg/Th17 cells was lower in patients with DCM than that in healthy donors. These findings were in agreement with those of study from Wang et al. [12]. Moreover, we demonstrated the elevation of RGC-32 levels was accompanied by the increased frequency of Th17 cells. Importantly, Statistical analysis indicated the levels of RGC-32 in DCM patients displayed a high degree of correlation with the frequencies of Th17 and Treg cells as well as the ratio of Treg/Th17. Recently, several groups reported that Th17 and Treg cells can transform into each other during inflammatory environment and autoimmune diseases [41, 42]. Rus and workers [18] demonstrated RGC32 is preferentially upregulated during Th17 cells differentiation. RGC-32\% mice have normal Th1, Th2, and regulatory T cell differentiation but show defective Th17 differentiation in vitro. Based on these data, we speculated that the overexpression of RGC-32 may contribute to the imbalance Treg/Th17 cells through upregulation of Th17 in DCM, but further studies are needed to verify this idea. In addition, the mechanism underlying that the levels of RGC32 are uncorrelated with the frequencies of Th17 and Treg cells in healthy control subjects is currently unknown.

It is determined that the RGC-32 is expressed in PBMCs, lymphocytes, macrophages [8, 43]. To further examine the effect of RGC-32 on the frequencies of Treg and Th17 cells, we conducted the overexpression or downregulation of RGC-32 in PBMCs from patients with DCM, and found the expression of RGC-32 was in direct correlation with the frequencies of Treg and Th17 cells. The results further support RGC-32 can affect the frequencies of Treg and Th17 cells, and then contribute to progression of DCM by promoting the disequilibrium between Th17andTreg cells.

\section{Conclusion}

Our study demonstrated that increased levels of plasma RGC-32 positively correlated with the elevation of circulating Th17 frequency, and while negatively correlated with the decline of Treg frequency and Treg/Th17 ratio in patients with DCM. In summary, our data are the first demonstration that RGC-32 is involved in the imbalance of Treg/Th17 ratio and thereby disrupting inflammatory immune reactions occurring in the heart of DCM patients. Further studies are needed to evaluate the detailed mechanisms of RGC-32 promoting the imbalance of Treg/Th17 in patients with DCM. 


\section{Cellular Physiology Cell Physiol Biochem 2017;43:1515-1525 and Biochemistry Published of $\begin{aligned} & \text { DOI: 10.1159/000481975 } \\ & \text { (c) } 2017 \text { The Author(s). Published by S. Karger AG, Basel } \\ & \text { www.karger.com/cpb }\end{aligned}$}

Li et al.: RGC-32 Promotes Treg/Th17 Imbalance in DCM

\section{Acknowledgements}

This work was supported by the National Natural Scientific Foundation of China (No. 81201780 to Bailing Li) and Changhai Scientific Foundation of China (No. CH125520706 to Bailing Li) and Shanghai Natural Science Fund (grant number 17ZR1438100 to Meng-Wei Tan, MD). The funders had no role in study design, data collection and analysis, decision to publish, or preparation of the manuscript.

\section{Disclosure Statement}

The authors declare that they have no Disclosure Statement.

\section{References}

1 Felker GM, Thompson RE, Hare JM, Hruban RH, Clemetson DE, Howard DL, Baughman KL, Kasper EK: Underlying causes and long-term survival in patients with initially unexplained cardiomyopathy. N Engl J Med 2000;342:1077-1084.

- 2 Jefferies JL, Towbin JA: Dilated cardiomyopathy. Lancet 2010;375:752-762.

-3 Mobini R, Maschke H, Waagstein F: New insights into the pathogenesis of dilated cardiomyopathy: possible underlying autoimmune mechanisms and therapy. Autoimmun Rev 2004;3:277-284.

- 4 Pankuweit S, Portig I, Maisch B: Pathophysiology of cardiac inflammation: molecular mechanisms. Herz 2002;27:669-676.

-5 Badea T, Niculescu F, Soane L, Fosbrink M, Sorana H, Rus V, Shin ML, Rus H: RGC-32 increases p34CDC2 kinase activity and entry of aortic smooth muscle cells into S-phase. J Biol Chem 2002;277:502-508.

-6 Liu H, Shen Y, Sun L, Kuang X, Zhang R, Zhang H, Zhou J, Li X, Huang W: [Effects of response gene to complement 32 as a new biomarker in children with acute kidney injury]. Zhonghua Er Ke Za Zhi 2014;52:494-499.

7 Tegla CA, Cudrici CD, Nguyen V, Danoff J, Kruszewski AM, Boodhoo D, Mekala AP, Vlaicu SI, Chen C, Rus V, Badea TC, Rus H: RGC-32 is a novel regulator of the T-lymphocyte cell cycle. Exp Mol Pathol 2015;98:328337.

- 8 Tegla CA, Cudrici CD, Azimzadeh P, Singh AK, Trippe R, 3rd, Khan A, Chen H, Andrian-Albescu M, Royal W, 3rd, Bever C, Rus V, Rus H: Dual role of Response gene to complement-32 in multiple sclerosis. Exp Mol Pathol 2013;94:17-28.

-9 Vlaicu SI, Tegla CA, Cudrici CD, Fosbrink M, Nguyen V, Azimzadeh P, Rus V, Chen H, Mircea PA, Shamsuddin A, Rus H: Epigenetic modifications induced by RGC-32 in colon cancer. Exp Mol Pathol 2010;88:67-76.

- 10 Baba A, Yoshikawa T, Ogawa S: Autoantibodies produced against sarcolemmal Na-K-ATPase: possible upstream targets of arrhythmias and sudden death in patients with dilated cardiomyopathy. J Am Coll Cardiol 2002;40:1153-1159.

-11 Baba A: Autoantigen estimation and simple screening assay against cardiodepressant autoantibodies in patients with dilated cardiomyopathy. Ther Apher Dial 2008;12:109-116.

12 Li J, Wang L, Wang S, Zhu H, Ye P, Xie A, Shen B, Liu C, Guo C, Fu Q, Zhang K, Xia J: The Treg/Th17 imbalance in patients with idiopathic dilated cardiomyopathy. Scand J Immunol 2010;71:298-303.

13 Rus V, Nguyen V, Tatomir A, Lees JR, Mekala AP, Boodhoo D, Tegla CA, Luzina IG, Antony PA, Cudrici CD, Badea TC, Rus HG: RGC-32 Promotes Th17 Cell Differentiation and Enhances Experimental Autoimmune Encephalomyelitis. J Immunol 2017;198:3869-3877.

14 Li C, Yuan J, Zhu YF, Yang XJ, Wang Q, Xu J, He ST, Zhang JA: Imbalance of Th17/Treg in Different Subtypes of Autoimmune Thyroid Diseases. Cell Physiol Biochem 2016;40:245-252.

15 Baldeviano GC, Barin JG, Talor MV, Srinivasan S, Bedja D, Zheng D, Gabrielson K, Iwakura Y, Rose NR, Cihakova D: Interleukin-17A is dispensable for myocarditis but essential for the progression to dilated cardiomyopathy. Circ Res 2010;106:1646-1655.

16 Chen P, Baldeviano GC, Ligons DL, Talor MV, Barin JG, Rose NR, Cihakova D: Susceptibility to autoimmune myocarditis is associated with intrinsic differences in CD4(+) T cells. Clin Exp Immunol 2012;169:79-88. 


\section{Cellular Physiology Cell Physiol Biochem 2017;43:1515-1525

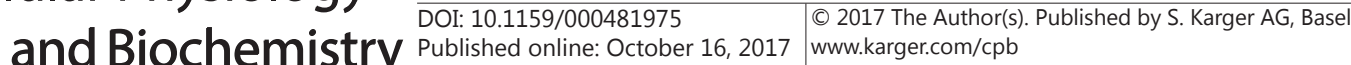

Li et al.: RGC-32 Promotes Treg/Th17 Imbalance in DCM

17 Stephenson E, Savvatis K, Mohiddin SA, Marelli-Berg FM: T-cell immunity in myocardial inflammation: pathogenic role and therapeutic manipulation. Br J Pharmacol 2016. DOI:10.1111/bph.13613.

18 Rus V, Nguyen V, Tatomir A, Lees JR, Mekala AP, Boodhoo D, Tegla CA, Luzina IG, Antony PA, Cudrici CD, Badea TC, Rus HG: RGC-32 Promotes Th17 Cell Differentiation and Enhances Experimental Autoimmune Encephalomyelitis. J Immunol 2017;198: 3869-3877.

19 Richardson P, McKenna W, Bristow M, Maisch B, Mautner B, O’Connell J, Olsen E, Thiene G, Goodwin J, Gyarfas I, Martin I, Nordet P: Report of the 1995 World Health Organization/International Society and Federation of Cardiology Task Force on the Definition and Classification of cardiomyopathies. Circulation 1996;93:841-842.

20 Zhang WC, Wang YG, Wei WH, Xiong X, Liu KL, Wang DH, Hu XF, Peng YD, Wu JJ, Cheng LX: Activated Circulating Myeloid-Derived Suppressor Cells in Patients with Dilated Cardiomyopathy. Cell Physiol Biochem 2016;38:2438-2451.

21 Nakayama T, Sugano Y, Yokokawa T, Nagai T, Matsuyama TA, Ohta-Ogo K, Ikeda Y, Ishibashi-Ueda H, Nakatani T, Ohte N, Yasuda S, Anzai T: Clinical impact of the presence of macrophages in endomyocardial biopsies of patients with dilated cardiomyopathy. Eur J Heart Fail 2017;19:490-498.

-22 Wu Y, Wan T, Zhou X, Wang B, Yang F, Li N, Chen G, Dai S, Liu S, Zhang M, Cao X: Hsp70-like protein 1 fusion protein enhances induction of carcinoembryonic antigen-specific CD8+ CTL response by dendritic cell vaccine. Cancer Res 2005;65:4947-4954.

23 Ding JW, Zheng XX, Zhou T, Tong XH, Luo CY, Wang XA: HMGB1Modulates the Treg/Th17 Ratio in Atherosclerotic Patients. J Atheroscler Thromb 2016;23:737-745.

24 Zhao J, Ma J, Zhang X, Li Q, Yang X: Equilibrium of Treg/Th17 cells of peripheral blood in syphilitic patients with sero-resistance. Exp Ther Med 2016;11:2300-2304.

-25 Sun Q, Yao X, Ning Y, Zhang W, Zhou G, Dong Y: Overexpression of response gene to complement 32 (RGC32) promotes cell invasion and induces epithelial-mesenchymal transition in lung cancer cells via the NFkappaB signaling pathway. Tumour Biol 2013;34:2995-3002.

-26 Kirchhof MG, Chau LA, Lemke CD, Vardhana S, Darlington PJ, Marquez ME, Taylor R, Rizkalla K, Blanca I, Dustin ML, Madrenas J: Modulation of T cell activation by stomatin-like protein 2. J Immunol 2008;181:1927-1936.

27 Homey B: [After TH1/TH2 now comes Treg/TH17: significance of T helper cells in immune response organization]. Hautarzt 2006;57:730-732.

28 Vlaicu SI, Cudrici C, Ito T, Fosbrink M, Tegla CA, Rus V, Mircea PA, Rus H: Role of response gene to complement 32 in diseases. Arch Immunol Ther Exp (Warsz) 2008;56:115-122.

29 Tanaka T, Takada H, Nomura A, Ohga S, Shibata R, Hara T: Distinct gene expression patterns of peripheral blood cells in hyper-IgE syndrome. Clin Exp Immunol 2005;140:524-531.

-30 Korn T, Bettelli E, Oukka M, Kuchroo VK: IL-17 and Th17 Cells. Annu Rev Immunol 2009;27:485-517.

31 Patel DD, Kuchroo VK: Th17 Cell Pathway in Human Immunity: Lessons from Genetics and Therapeutic Interventions. Immunity 2015;43:1040-1051.

-32 Liu Y, Su L, Lin Q, Han Y, You P, Fan Q: Induction of C-Mip by IL-17 Plays an Important Role in AdriamycinInduced Podocyte Damage. Cell Physiol Biochem 2015;36:1274-1290.

-33 Holtta V, Klemetti P, Sipponen T, Westerholm-Ormio M, Kociubinski G, Salo H, Rasanen L, Kolho KL, Farkkila M, Savilahti E, Vaarala O: IL-23/IL-17 immunity as a hallmark of Crohn's disease. Inflamm Bowel Dis 2008;14:1175-1184.

34 Mizui M, Koga T, Lieberman LA, Beltran J, Yoshida N, Johnson MC, Tisch R, Tsokos GC: IL-2 protects lupusprone mice from multiple end-organ damage by limiting CD4-CD8- IL-17-producing T cells. J Immunol 2014;193:2168-2177.

-35 Lock C, Hermans G, Pedotti R, Brendolan A, Schadt E, Garren H, Langer-Gould A, Strober S, Cannella B, Allard J, Klonowski P, Austin A, Lad N, Kaminski N, Galli SJ, Oksenberg JR, Raine CS, Heller R, Steinman L: Gene-microarray analysis of multiple sclerosis lesions yields new targets validated in autoimmune encephalomyelitis. Nat Med 2002;8:500-508.

-36 Kebir H, Kreymborg K, Ifergan I, Dodelet-Devillers A, Cayrol R, Bernard M, Giuliani F, Arbour N, Becher B, Prat A: Human TH17 lymphocytes promote blood-brain barrier disruption and central nervous system inflammation. Nat Med 2007;13:1173-1175.

-37 Jandus C, Bioley G, Rivals JP, Dudler J, Speiser D, Romero P: Increased numbers of circulating polyfunctional Th17 memory cells in patients with seronegative spondylarthritides. Arthritis Rheum 2008;58:2307-2317. 


\section{Cellular Physiology Cell Physiol Biochem 2017;43:1515-1525

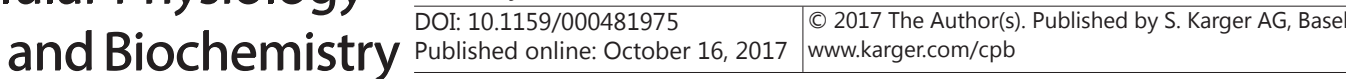 \\ Li et al.: RGC-32 Promotes Treg/Th17 Imbalance in DCM}

-38 Bovenschen HJ, van de Kerkhof PC, van Erp PE, Woestenenk R, Joosten I, Koenen HJ: Foxp3+ regulatory T cells of psoriasis patients easily differentiate into IL-17A-producing cells and are found in lesional skin. J Invest Dermatol 2011;131:1853-1860.

39 Sasaki N, Yamashita T, Takeda M, Hirata K: Regulatory T cells in atherogenesis. J Atheroscler Thromb 2012;19:503-515.

40 Rock KL, Latz E, Ontiveros F, Kono H: The sterile inflammatory response. Annu Rev Immunol 2010;28:321342.

-41 Singh K, Gatzka M, Peters T, Borkner L, Hainzl A, Wang H, Sindrilaru A, Scharffetter-Kochanek K: Reduced CD18 levels drive regulatory T cell conversion into Th17 cells in the CD18hypo PL/J mouse model of psoriasis. J Immunol 2013;190:2544-2553.

42 Sharma MD, Hou DY, Liu Y, Koni PA, Metz R, Chandler P, Mellor AL, He Y, Munn DH: Indoleamine 2, 3-dioxygenase controls conversion of Foxp3+ Tregs to TH17-like cells in tumor-draining lymph nodes. Blood 2009;113:6102-6111.

43 Tang R, Zhang G, Chen SY: Response gene to complement 32 protein promotes macrophage phagocytosis via activation of protein kinase C pathway. J Biol Chem 2014;289:22715-22722. 